\title{
FIRM PRODUCTIVITY, PROFIT AND BUSINESS GOAL SATISFACTION: AN ASSESSMENT OF MAINTENANCE DECISION EFFECTS ON SMALL AND MEDIUM SCALE ENTERPRISES (SME'S)
}

\author{
Daniel Owusu-Mensah®a, Evans K. Quaye ${ }^{b}$, Lydia Brakoc \\ aSchool of Mechanical Engineering, Jiangsu University, Zhenjiang, 212013, China. \\ bSchool of Advanced Technology engineering and sciences, Accra Institute of Technology, Accra, Ghana. \\ cSchool of Medicine, Jiangnan University, Wuxi, China.
}

\begin{abstract}
:
This study was carried out to identify which factors are most relevant to managers of SMEs in maintenance decision making, and to investigate how these factors influence the realization of business goals satisfactorily, using structural equation modelling, partial least square design (PLS-SEM) to establish significant relationships between manifest and latent variables. A study of maintenance cost vis a vis the number of maintenance works carried out and profits realized was conducted to ascertain correlations and identify which factors played key roles in profit maximization. Results showed that with increasing level of maintenance for SMEs, profit margins reduced significantly. Also, an $R^{2}$ value of 0.83 showed that the latent variable, business goal satisfaction was explained to a high degree (83\%) by the manifest variables. Rentals of equipment from third parties $(0.27)$, halting production $(0.11)$ and outsourcing $(0.39)$ were less considered for business sustainability per correlation coefficients than funds (0.79), and the possibilities to carry out both corrective $(0.64)$ and preventive (0.58) maintenance works. F-square value greater than zero was realized $(0.387)$ and this showed reliability of the both inner and outer models. These findings can be used in building a decision tool or framework that will best suit SMEs with high financial budget constraints.
\end{abstract}

Keywords: maintenance decision making, funds availability, business goals satisfaction.

Cite as: Sunil, K., Arun, G. (2021). Firm productivity, profit and business goal satisfaction: an assessment of maintenance decision effects on Small and Medium Scale Enterprises (SME's). J Appl Res Eng Technol \& Engineering, 2(1), $23-31$. https://doi.org/10.4995/jarte.2021.14615

\section{Introduction}

The sustainability of any business depends on an appropriate management of its resources from raw materials, equipment, personnel and funds, as well as on its style of management. The ability for business owners or managers to decide on issues relevant to the achievement of the goals of the business is key. Most businesses are based on a production system model, where a range of machinery or equipment are needed to transform raw materials (inputs) into outputs (Parida \& Kumar, 2016). Depending on the nature of raw material and the organizational standards for production, different levels of raw material transformation efficiency can be expected (Al-Tabbaa and Ankrah, 2016). On the other hand, production machinery efficiency is key to the overall performance of a complete production system (Ma et al., 2018; Ruschel et al., 2017; Van et al., 2012). However, it is inevitable that machinery become less efficient, and may eventually fail as they age due to degradation regardless of their initial efficiency, make or operation (Verbet et al., 2017; Jiang \& Murthy, 2008). The impact of malfunctioning machinery on an organization's performance and market competition can vary from mild to devastating, as certain machine failures may even result in the loss of lives.
Economically, machinery failure can lead to reduction in production or to a complete halt, leading to economic losses, dissatisfied consumer base and loss of business reputation (Ma et al., 2018; Jiang \& Murthy, 2008). Most often than not, machinery or equipment failures are more costly as they usually occur unexpectedly and require expenditure that has not been previously budgeted. This may lead to a long period of lack of production especially for huge and expensive machinery. It therefore becomes expedient that organizations make plans towards the prevention of scenarios that may cause their folding out of business or that may prevent them from realizing their productivity goals, hence maintenance (Parida \& Kumar, 2016; Marquez \& Gupta, 2006; Jiang and Murthy, 2008).

Maintenance carried out in an organization is intended to satisfy specific organizational goal, and in line with organizational strategy (Liu et al., 2017; Ma et al., 2018; Bertolini \& Bevilacqua, 2006). The maintenance of machinery or equipment of an organization has two major direct benefits; to ensure that the maintained equipment or machine is working properly and according to specification, and to correct any potential malfunctions that may hinder efficient performance (Olivotti et al., 2018; Shen \& Zhu, 2017). Thus, maintenance can be a preventive measure or corrective one, depending which is relevant at a point in time (Qiu et al., 2017). 
Indirectly, maintenance can be related to an organization's vision of becoming the leading producer of high quality goods and services in the long term or to the potential of the organization to cut down on overhead costs from use of malfunctioning machinery, or to avoid consumer dissatisfaction and loss of loyalty to organization's products/services brands (Ma et al., 2018; Jiang \& Murthy, 2008; Lee, 2005). Direct costs such restoration of degraded machinery components or a total replacement to ensure smooth operation are always expected. However, the indirect costs associated with machinery failure such as delayed delivery, loss of customers due to dissatisfaction and negative word-of-mouth are much higher costs to pay. This make it extremely relevant that maintenance is embedded in the daily management of an organization to ensure readiness to overcome unexpected failures and as well prevent or reduce such negative impacts to their barest minimum levels (Bertolini \& Bevilacqua, 2006; Lee, 2005).

Nonetheless, little information is available on the effects of maintenance decision variables, as applied to management maintenance decision making, on the productivity and profitability of manufacturing firms with both short- and long-term business goals in perspective. This study therefore seeks to address this challenge by comparing the way maintenance decision variables influence maintenance behavior of selected firms in Ghana and assess impacts on profitability, productivity, customer and business goal satisfaction, as well as the cost/benefit analysis in the long and short terms. This study is beyond the usual modelling of maintenance, and attempts to understand the actual practicality of carrying out maintenance, the actual decision determinants beyond theory, and how these decisions influence business sustainability in general, with findings relevant to maintenance policy development.

\section{Materials and method}

The study focuses on identifying relevant factors that influence management maintenance decision making firstly, and then proceed with analysis of effects as earlier stated. A structural equation modelling with partial least square (PLS-SEM) design is followed to ascertain the correlation between independent and latent dependent variables such as customer satisfaction based on the European customer satisfaction index (ECSI) In identifying variables that influence management decision on whether to carry out a maintenance on part or whole systems within their firms, questionnaires were distributed with open ended question on what concerns were more important to them in deciding whether or not to carry out preventive or corrective maintenance. Secondary data were also collected on maintenance history as well as profit made over a period of six years of production. These variables were then classified into categories and assessed to ascertain how they influenced perceived business goal satisfaction of managers and how it influenced their productivity and profit margins over the studied period.

In the context of construct measurement, the questionnaire was structured to evaluate the relationship existing between six main constructs which includes funds availability, outsourcing, preventive maintenance, corrective maintenance, rentals, halting production and satisfaction of business goals. In details funds availability contains three measurement items which includes whether firms have enough funds to carry out needed maintenance, cost of management outweigh the benefits of other options and carrying out maintenance exhaust the budget needed for other resources. In a similar manner, outsourcing was also measured using three items which includes whether benefits are higher than the costs to outsource production, standard of products can be compromised by outsourcing and outsourcing can yield higher profits then self-production. Preventive maintenance on the other comprised of whether preventive maintenance will best suit current need of firms, preventive maintenance will be an option preferred to corrective maintenance and whether a firm can carry out preventive maintenance whereas corrective measurement embraced whether this construct will best suit the current need of firms, to what extant this option is preferred and if firms can carry out corrective measurement. The study further measured rentals also using three item scale capturing whether rent from a third party will help the firm, consideration of renting cost and

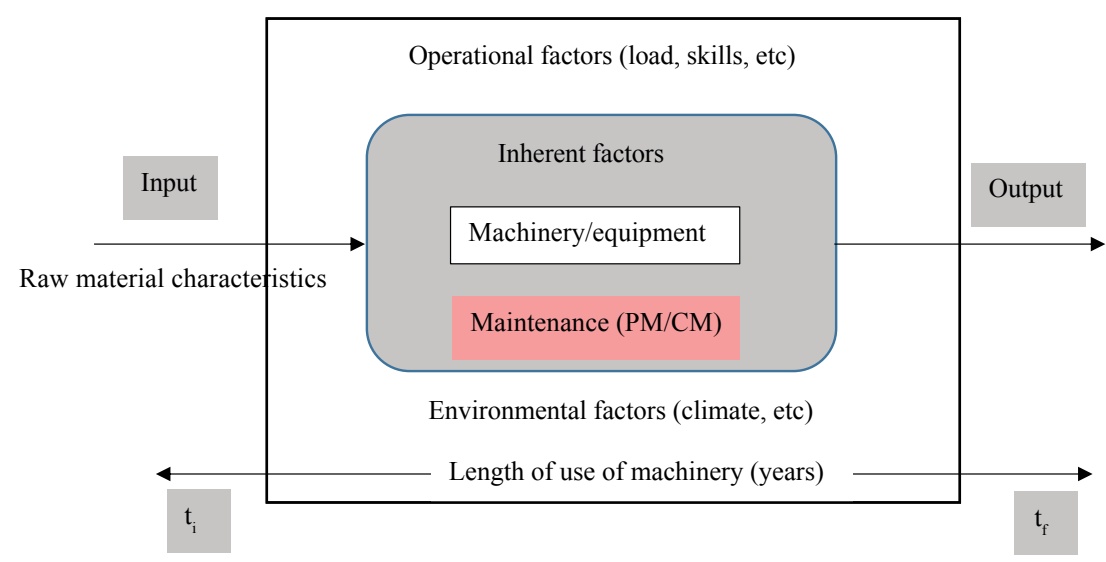

Figure 1: Diagram of a production system setup and conditions influencing machinery functionality over a period of usage $\left(t_{i}\right.$, initial time and $t_{f}$, final time) with maintenance in perspective. PM, preventive maintenance; $C M$, corrective maintenance. 
Firm productivity, profit and business goal satisfaction: an assessment of maintenance decision effects on Small and Medium Scale Enterprises (SME's)

effect on revenue per productivity and whether rentals as an option can maintain its quality level. On the side of latent variable Halting production, four measurement items were assigned which includes whether stopping production is an option to carry out maintenance generally, whether halting will be more beneficial than deciding to carry out maintenance, whether halting earn firms the ability to remain in business in any other way and whether halting has the potential to save money for maintenance. Satisfaction of business goals serving as the main response latent or construct variable in our structural model was relative to only two measurement items which includes whether decision to carry out maintenance help realize the goals of firms and also whether one prefers maintenance to any other option in business goal attainment. Generally, all the measurement items for the respective constructs or latent variables proposed in the study were assessed on a five-point Likert scale with scale poles ranging from strongly disagree to strongly agree. Summarily, of various constructs and their respective measurement items together with corresponding scales are list in Table 1.

\section{Empirical Results and Discussion}

\subsection{Preliminary Analysis}

\subsubsection{Test of Normality}

The in the first place conducted a normality test to determine the distribution of the data as depicted in Table 2.

Table 1: Variables for PLS-SEM questionnaire. Instruction: Score the following questions on a scale of 1-5 on their relevance in maintenance decision making.

\begin{tabular}{|c|c|c|}
\hline Constructs & Indicator & Scale items \\
\hline \multirow{3}{*}{ Funds availability } & FUNDS1 & Q1: Does the firm have enough funds to carry out the needed maintenance? \\
\hline & FUNDS2 & Q2: Will the cost of maintenance outweigh the benefits of other options? \\
\hline & FUNDS3 & Q3: Will carrying out maintenance exhaust the budget needed for other resources? \\
\hline \multirow{3}{*}{ Outsourcing } & OUTSOURC4 & Q4: Are the benefits higher than the costs to outsource production? \\
\hline & OUTSOURC5 & Q5: Will the standard of products be compromised by outsourcing? \\
\hline & OUTSOURC6 & Q6: Will outsourcing yield higher profits than producing yourself? \\
\hline \multirow{3}{*}{ Preventive maintenance } & PM7 & Q7: Score the extent to which you think PM will best suit the current need of the firm \\
\hline & PM8 & Q8: To what extent will this option be preferred to CM? \\
\hline & PM9 & Q9: Can the firm carry out PM at the moment? How will this affect the ability to carry out other tasks? \\
\hline \multirow{3}{*}{ Corrective maintenance } & CM10 & Q10: Score the extent to which you think CM will best suit the current need of the firm. \\
\hline & CM11 & Q11: To what extent will this option be preferred to CM? \\
\hline & CM12 & Q12: Can the firm carry out CM at the moment? How will this affect the ability to carry out other tasks? \\
\hline \multirow{3}{*}{ Rentals } & RENT13 & Q13: Will the option to rent from a third party help the firm? \\
\hline & RENT14 & Q14: Consider renting cost and effect on revenue per productivity and rate \\
\hline & RENT15 & Q15: Will this option maintain quality level? \\
\hline \multirow{4}{*}{ Halting production } & HALT16 & Q16: How do you rate stopping production as an option to carrying out maintenance generally? \\
\hline & HALT17 & Q17: Will halting be more beneficial than deciding to carry out maintenance? \\
\hline & HALT18 & Q18: Will halting earn the firm the ability to remain in business in any other way? \\
\hline & HALT19 & Q19: Halting has the potential to save money for maintenance. Please rate. \\
\hline \multirow{2}{*}{ Satisfaction of business goals } & BUS-SATISF20 & Q20: Will the decision to carry out maintenance help realize the goals of the firm? \\
\hline & BUS-SATISF21 & Q21: Will you prefer maintenance to any other option in business goal attainment? \\
\hline
\end{tabular}

Table 2: Test of Normality of Constructs.

\begin{tabular}{|c|c|c|c|c|c|c|}
\hline \multirow[b]{2}{*}{ Factors } & \multicolumn{3}{|c|}{ Kolmogorov-Smirnov } & \multicolumn{3}{|c|}{ Shapiro-Wilk } \\
\hline & Statistic & df & Sig. & Statistic & df & Sig. \\
\hline \multirow{2}{*}{$\begin{array}{l}\text { FUINDS1 } \\
\text { FUNDS2 }\end{array}$} & 0.312 & 300 & 0.000 & 0.721 & 300 & 0.000 \\
\hline & 0.337 & 261 & 0.000 & 0.652 & 261 & 0.004 \\
\hline \multirow{2}{*}{$\begin{array}{l}\text { FUNDS3 } \\
\text { OUTSOURC4 }\end{array}$} & 0.262 & 300 & 0.025 & 0.761 & 300 & 0.000 \\
\hline & 0.264 & 261 & 0.000 & 0.760 & 261 & 0.035 \\
\hline \multirow{2}{*}{$\begin{array}{l}\text { OUTSOURC5 } \\
\text { OUTSOURC6 }\end{array}$} & 0.230 & 300 & 0.039 & 0.878 & 300 & 0.002 \\
\hline & 0.257 & 261 & 0.000 & 0.840 & 261 & 0.000 \\
\hline \multirow{2}{*}{$\begin{array}{l}\text { PM7 } \\
\text { PM8 }\end{array}$} & 0.255 & 300 & 0.000 & 0.851 & 300 & 0.010 \\
\hline & 0.233 & 261 & 0.001 & 0.842 & 261 & 0.001 \\
\hline \multirow{2}{*}{$\begin{array}{l}\text { PM9 } \\
\text { CM10 }\end{array}$} & 0.171 & 300 & 0.006 & 0.910 & 300 & 0.000 \\
\hline & 0.165 & 261 & 0.015 & 0.885 & 261 & 0.005 \\
\hline \multirow{2}{*}{$\begin{array}{l}\text { CM11 } \\
\text { CM12 }\end{array}$} & 0.179 & 300 & 0.000 & 0.912 & 300 & 0.020 \\
\hline & 0.194 & 261 & 0.035 & 0.908 & 261 & 0.000 \\
\hline \multirow{2}{*}{$\begin{array}{l}\text { RENT13 } \\
\text { RENT14 }\end{array}$} & 0.208 & 300 & 0.001 & 0.898 & 300 & 0.005 \\
\hline & 0.203 & 261 & 0.012 & 0.904 & 261 & 0.003 \\
\hline \multirow{2}{*}{$\begin{array}{l}\text { RENT15 } \\
\text { HALT16 }\end{array}$} & 0.184 & 300 & 0.000 & 0.906 & 300 & 0.005 \\
\hline & 0.220 & 261 & 0.000 & 0.905 & 261 & 0.015 \\
\hline \multirow{2}{*}{$\begin{array}{l}\text { HALT17 } \\
\text { HALT18 }\end{array}$} & 0.219 & 300 & 0.011 & 0.896 & 300 & 0.000 \\
\hline & 0.226 & 261 & 0.030 & 0.902 & 261 & 0.001 \\
\hline HALT19 & 0.205 & 300 & 0.000 & 0.897 & 300 & 0.000 \\
\hline BUS-SATISF20 & 0.216 & 261 & 0.003 & 0.903 & 261 & 0.020 \\
\hline BUS-SATISF21 & 0.230 & 261 & 0.030 & 0.832 & 261 & 0.015 \\
\hline
\end{tabular}


Table 2 represents the normality test of the data. It must be noted that the type of analytical technique or process used to analyze data is dependent on the distribution of the data. When the data is skewed positively or negatively; the researcher must employ a non-parametric test whiles a normally distributed data (Gaussian distribution) requires parametric test analysis. The test criteria as suggested by Stebbins (2001) are to obtain a Shapiro Wilks test value in excess of.05. From Table 2, the analyzed data shows that all the parameters obtained a $p$ value in excess of 0.5 and this is an indication that the data is normally distributed hence the justification for the use of parametric test procedure for the entire analysis.

\subsubsection{Test of Internal consistency and Reliability}

A key element in the process of checking the integrity of the data is to examine the internal consistency of the factors to be analyzed. This is necessary to establish the extent to which they can measure and turn out the desired outcome to achieve valid conclusions. The study conducted the Cronbach alpha correlation coefficient using the SPSS analytical tool. As observed in Table 2 each of the values obtained exceed the Cronbach alpha correlation threshold of 0.7 as posited by Pallant (2007). Thus, the items to be analyzed (Funds availability, Outsourcing, Preventive maintenance, Corrective maintenance, Rentals, Halting production and satisfaction of business goals constructs) meet the strict level of integrity for further analysis. Table 3 thus shows the internal consistency and reliability test of the constructs.

Table 3: Test of internal consistency and reliability.

\begin{tabular}{lccc}
\hline Factors & $\begin{array}{c}\text { Scale Mean if } \\
\text { Item Deleted }\end{array}$ & $\begin{array}{c}\text { Scale } \\
\text { Variance if } \\
\text { Item Deleted }\end{array}$ & $\begin{array}{c}\text { Cronbach's } \\
\text { Alpha if Item } \\
\text { Deleted }\end{array}$ \\
\hline FUINDS1 & 84.110 & 319.924 & 0.943 \\
\hline FUNDS2 & 84.224 & 322.287 & 0.803 \\
FUNDS3 & 84.772 & 315.687 & 0.743 \\
\hline OUTSOURC4 & 84.501 & 324.797 & 0.944 \\
\hline OUTSOURC5 & 85.075 & 310.376 & 0.742 \\
\hline OUTSOURC6 & 85.455 & 310.241 & 0.941 \\
\hline PM7 & 85.773 & 310.921 & 0.941 \\
\hline PM8 & 85.472 & 310.285 & 0.941 \\
\hline PM9 & 85.683 & 311.461 & 0.941 \\
\hline CM10 & 85.754 & 312.866 & 0.751 \\
\hline CM11 & 85.280 & 310.773 & 0.811 \\
\hline CM12 & 85.563 & 311.465 & 0.941 \\
\hline RENT13 & 84.632 & 313.352 & 0.729 \\
\hline RENT14 & 85.328 & 311.169 & 0.941 \\
\hline RENT15 & 84.509 & 334.943 & 0.821 \\
\hline HALT16 & 80.655 & 299.047 & 0.701 \\
\hline HALT17 & 85.104 & 370.320 & 0.810 \\
\hline HALT18 & 84.323 & 315.117 & 0.728 \\
\hline HALT19 & 86.794 & 310.82 & 0.915 \\
\hline BUS-SATISF20 & 85.140 & 319.163 & 0.816 \\
\hline BUS-SATISF21 & & & \\
\hline
\end{tabular}

\subsubsection{Kaiser-Meyer-Olklin (KMO) and Bartlett's Test}

The Kaiser-Meyer-Olkin (KMO) sampling adequacy measure and Bartlett's sphericity test test help indicate whether the data used in this analysis is sufficient for the identification of structures. In particular, the KMO test is a measure that indicates the proportion of variation that may be caused by such underlying variables. The test value of the KMO for the constructs used in the study (Availability of funds, Outsourcing, Preventive maintenance, Corrective maintenance, Rentals, Halting development and fulfillment of business objectives constructs) was given as 0.844 from Table 4 . This value is very high (closer to 1) and thus gives the overall impression that the variables under consideration have clarified a large proportion of variance (about 84.4 percent). The value of the KMO test also provides an indicator that the sample is suitable for factor analysis. In addition, the Bartlett Sphericity Test checks the hypothesis that an identity matrix is the matrix of correlation. This means that the variables within a particular construct are unrelated and thus inadequate for the identification of structures. The Bartlett sphericity test from Table 4 gives a p-value lower than the degree of significance that contributes to the hypothesis being dismissed. This then suggests that the variables in the matrix of correlation are related and therefore ideal for the identification of structures (factor analysis). In short, these tests (Kaiser-Meyer-Olkin (KMO) and Bartlett's test) demonstrate that the data used in the study is appropriate for the identification of structures or factor analysis. Table 4 shows results from the KMO and Bartlett's test.

Table 4: KMO and Bartlett's test.

\begin{tabular}{ccc}
\hline Kaiser-Meyer-Olkin Measure of Sampling Adequacy & 0.844 \\
\hline \multirow{3}{*}{ Bartlett's Test of Sphericity } & Approx. Chi-square & 456.179 \\
& Df & 36 \\
& Sig. & 0.000 \\
\hline
\end{tabular}

\subsubsection{Exploratory Factor Analysis (EFA)}

In Table 5, the results of the exploratory factor analysis (EFA) are presented. All measurement products based on their high factor loadings, were retained given the fund raising framework. 20.76 percent of the variation for the products was clarified by the fund-raising structure and had a value of 4,756 . For all the three things held, the Cronbach alpha was 0.91 for the variable. In addition, all three outsourcing build measurement items were kept, even based on their strong factor loadings. The threeitem outsourcing structure had a value of 2.575 and 12.88 percent of the difference for the retained products was clarified. The alpha for this element in Cronbach was 0.82 . All the measurement variables were maintained with respect to the "preventive maintenance" construct as they had their respective factor loadings to be more than 0.5 . With respect to its measurement objects, the preventive maintenance construct clarified 8.87 percent of variance with an eigen value of 1.454 and an alpha value of Cronbach of 0.89 . Based on their successful factor loadings, all three items for the corrective maintenance were retained. The three-things of the corrective maintenance structure had a value of 1.368 and explained $7.85 \%$ of the difference for the items retained. The alpha of Cronbach for this element was 0.85 . In the case of rentals also as a construct (latent) variable, all times assumed to measure the aforementioned construct were retained due their respective high factor loading with a variance of 5.010, eigen value of 2.204, and a Cronbach's alpha value of 0.96 . Last but not least, as their respective factor loadings are seen to be greater than the threshold, none 
Firm productivity, profit and business goal satisfaction: an assessment of maintenance decision effects on Small and Medium Scale Enterprises (SME's)

Table 5: Exploratory factor analysis (EFA) for relationship governance constructs.

\begin{tabular}{|c|c|c|c|c|}
\hline Factor and items & Factor loadings & Eigen val. & Percentage variance & Cronbach's Alpha \\
\hline Funds availability & & 4.756 & 20.761 & 0.918 \\
\hline FUINDS1 & 0.848 & & & \\
\hline FUNDS2 & 0.683 & & & \\
\hline FUNDS3 & 0.619 & & & \\
\hline Outsourcing & & 2.575 & 12.883 & 0.820 \\
\hline OUTSOURC4 & 0.789 & & & \\
\hline OUTSOURC5 & 0.733 & & & \\
\hline OUTSOURC6 & 0.663 & & & \\
\hline Preventive maintenance & & 1.454 & 8.870 & 0.876 \\
\hline PM7 & 0.782 & & & \\
\hline PM8 & 0.630 & & & \\
\hline PM9 & 0.585 & & & \\
\hline Corrective maintenance & & 1.368 & 7.852 & 0.85 \\
\hline CM10 & 0.880 & & & \\
\hline CM11 & 0.873 & & & \\
\hline CM12 & 0.817 & & & \\
\hline Rentals & & 2.204 & 5.010 & 0.960 \\
\hline RENT13 & 0.868 & & & \\
\hline RENT14 & 0.883 & & & \\
\hline RENT15 & 0.860 & & & \\
\hline Halting production & & 2.827 & 4.709 & 0.912 \\
\hline HALT16 & 0.781 & & & \\
\hline HALT17 & 0.724 & & & \\
\hline HALT18 & 0.749 & & & \\
\hline HALT19 & 0.766 & & & \\
\hline Satisfaction of business goals & & 1.749 & 2.813 & 0.886 \\
\hline BUS-SATISF20 & 0.826 & & & \\
\hline BUS-SATISF21 & 0.813 & & & \\
\hline
\end{tabular}

of the four elements used to calculate the output of the construction halting was exempted (0.5). With respect to its measurement variables, this construct had its own value of 2.827 and clarified $4.709 \%$ of the variance retained in the products. The Cronbach's alpha for this construct was 0.91 . Finally, the response variable "business satisfaction goal with only two measurement items, all with significant factor loadings had an eigen value of 1.749 and 2.813 as the amount of variance explained by this factor with a Cronbach's alpha of 0.88 .

\subsection{Estimating the relationship between decision parameters and overall business goal satisfaction}

\subsubsection{Model Fit Assessment}

In structural equation modeling, an assessment of the measurement and structural model are performed simultaneously. According to Hair et al. (2016) the assessment of the measurement model usually should precede the model structure. The assessment of the overall measurement model fit was performed using confirmatory factor analysis (CFA) and the maximumlikelihood estimation technique to establish whether the model is acceptable. Thus, this exercise establishes how well the relationship between the observed indicators and the unobserved latent variables match the model, and as well specifying the pattern by which each measure loads on a particular factor Hair et al. (2016). In trying to determine if there was opportunity to improve the model, model fit indices were consulted. Accordingly, the error terms between and among retained or captured observed variables under each of the latent constructs were covaried. The observed variable under each latent variable were adequately correlated and met criteria of reliability and validity. Test of goodness-of-fit of the measurement model was performed using a range of indices tests including, the chi-square test $=1.409, \quad C F I=0.972$, RMSEA $=0.014$, and SRMR $=0.038$, PClose $=0.975$. These tests from Table 6 based on the column labeled give the indication that, the measurement model is a good fit. Following Joe et al (2017) cut-off criteria in covariance structure analysis, the values realized for factor structure analysis demonstrate sufficiently that, the complete measurement model including all the variables fit the data appropriately. This is presented in Table 6.

Table 6: Goodness of fit indexes.

\begin{tabular}{lccc}
\hline Measure & Estimate & Threshold & Interpretation \\
\hline CMIN & 516.921 & -------- & --------- \\
DF & 205 & -------- & --------- \\
CMIN/DF & 1.409 & Between 1 and 3 & Excellent \\
\hline CFI & 0.972 & $>0.950$ & Excellent \\
SRMR & 0.038 & $<0.081$ & Excellent \\
RMSEA & 0.014 & $<0.064$ & Excellent \\
\hline PClose & 0.975 & $>0.050$ & Excellent \\
Cutoff Criteria* & & & \\
Measure & Terrible & Acceptable & Excellent \\
\hline CMIN/DF & $>3$ & $<3$ & $>1$ \\
CFI & $<0.950$ & $>0.950$ & $>0.950$ \\
SRMR & $>0.080$ & $<0.080$ & $<0.080$ \\
\hline RMSEA & $>0.060$ & $<0.060$ & $<0.060$ \\
PClose & $<0.050$ & $>0.050$ & $>0.050$ \\
\hline
\end{tabular}




\subsubsection{Measurement Model Parameter estimates}

As shown in Table 7, the results of the measurement model parameter estimates show that all standardized loading or estimated values, including factor loadings variance were higher than the thresh-hold of 0.50 and statistically significant. All items were significantly associated with their specified constructs that is with relatively highly significant t-values ranging from 11.15 to 60.46 (t values $>|1.96|$ ). There were no negative error variances and no large standard errors. These results provide evidence for good fit of the measurement model. Thus, Table 7 represents the measurement model parameter estimates.

Table 7: Measurement model parameter estimates for variables of transaction dimensions and governance choice.

\begin{tabular}{|c|c|c|c|c|c|}
\hline $\begin{array}{l}\text { Latent } \\
\text { variables }\end{array}$ & & Indicators & $\begin{array}{l}\text { Standard- } \\
\text { ized test }\end{array}$ & $\begin{array}{l}\text { Standard } \\
\text { error }\end{array}$ & t-value \\
\hline \multirow{3}{*}{$\begin{array}{l}\text { Funds } \\
\text { availability }\end{array}$} & <--- & FUINDS1 & 0.740 & 0.049 & 25.715 \\
\hline & $<---$ & FUNDS2 & 0.891 & 0.049 & 25.973 \\
\hline & $<---$ & FUNDS3 & 0.913 & 0.041 & 26.597 \\
\hline \multirow{3}{*}{ Outsourcing } & $<--$ & OUTSOURC4 & 0.774 & 0.034 & 25.164 \\
\hline & $<---$ & OUTSOURC5 & 0.815 & 0.034 & 20.763 \\
\hline & $<---$ & OUTSOURC6 & 0.883 & 0.032 & 24.694 \\
\hline \multirow{3}{*}{$\begin{array}{l}\text { Preventive } \\
\text { maintenance }\end{array}$} & $<--$ & PM7 & 0.757 & 0.043 & 29.538 \\
\hline & $<---$ & PM8 & 0.815 & 0.048 & 11.153 \\
\hline & $<---$ & PM9 & 0.792 & 0.046 & 14.574 \\
\hline \multirow{3}{*}{$\begin{array}{l}\text { Corrective } \\
\text { maintenance }\end{array}$} & $<--$ & CM10 & 0.751 & 0.041 & 60.460 \\
\hline & $<---$ & CM11 & 0.736 & 0.023 & 55.833 \\
\hline & $<--$ & CM12 & 0.715 & 0.024 & 34.582 \\
\hline \multirow{3}{*}{ Rentals } & $<---$ & RENT13 & 0.854 & 0.043 & 12.478 \\
\hline & $<--$ & RENT14 & 0.713 & 0.056 & 17.190 \\
\hline & $<---$ & RENT15 & 0.803 & 0.057 & 16.981 \\
\hline \multirow{4}{*}{$\begin{array}{l}\text { Halting } \\
\text { production }\end{array}$} & $<---$ & HALT16 & 0.872 & 0.038 & 17.731 \\
\hline & $<---$ & HALT17 & 0.732 & 0.046 & 14.779 \\
\hline & $<--$ & HALT18 & 0.861 & 0.023 & 34.117 \\
\hline & $<---$ & HALT19 & 0.926 & 0.033 & 24.050 \\
\hline \multirow{2}{*}{$\begin{array}{l}\text { Satisfaction } \\
\text { of business } \\
\text { goals }\end{array}$} & $<--$ & BUS-SATISF20 & 0.829 & 0.020 & 19.190 \\
\hline & $<--$ & BUS-SATISF21 & 0.781 & 0.032 & 21.947 \\
\hline
\end{tabular}

In addition to assessing the reliability of the individual observed variables, composite reliability of all concepts exceeds the 0.70 benchmark for all constructs. This therefore gives the indication that, high levels of internal consistency reliability have been demonstrated among all four latent variables. Convergent validity was also assessed and was acceptable as almost all standardized factor loadings exceeded the 0.60 benchmark. For all factors, the AVE was above 0.50. Regarding discriminant validity, Alarcon et al. (2015) suggest that the square root of AVE of each latent variable can be used to establish discriminant validity, only if this value is larger than other correlation values among the latent variables. It can therefore be deduced from Table 8 that, the square roots of average variances extracted (AVEs) are all greater than the correlation values of their respective constructs. This result indicates that discriminant validity is well established. The square roots of average variances extracted (AVEs) are shown on diagonal, in bold in Table 7.

According to the algorithm quality criteria, an $R^{2}$ value of 0.83 showed that the latent variable, business goal satisfaction was explained to a high degree $(83 \%)$ by the manifest variables. Rentals of equipment from third parties (0.27), halting production (0.11) and outsourcing (0.39) were less considered for business sustainability per correlation coefficients than funds, and the possibilities to carry out both corrective (0.64) and preventive (0.58) maintenance works (Figure 2). F-square value greater than zero was realized $(0.387)$ and this showed reliability of the both inner and outer models.

According to Barone and Frangopol (2014), funds availability is a key determinant in the life-cycle maintenance of deteriorating structures as every maintenance objective has a cost implication that directly or indirectly affects a firm's profit margin and sustainability. For instance, if the sustainability of a business depends on the need to replace a production system, then funds become a key determinant of the sustenance of the business. This strongly correlated with the findings in this study as funds availability accounted for $79 \%$ of the satisfaction of business goals. This is more so considering the size of the firm, as categorized under SMEs. Another study considered the scheduling of preventive maintenance for modular designed components of an organization and identified the availability of funds as a major constraining factor in realizing maintenance goals (Joo, 2009).

Wherever availability of funds was mentioned it had to do with the purchase of spare parts or for other inventories needed for the performance of planned maintenance works, and so it is understandable that both PM and CM had significant influences in determining business goal satisfaction of firms as observed in this study (Yang et al., 2017). All maintenance costs, except other costs related to negative consumer behavior are directly subjected to funds availability. Several studies have been done on maintenance optimization in many areas such as transportation (Ma et al., 2018; Liu et al., 2015); power systems (Shayesteh et al., 2018); and renewable energy (Liu et al., 2017) among others, and the importance of funding showed as a key common factor (Nourelfath et al., 2015).

Table 8: Convergent and discriminant validities assessment.

\begin{tabular}{lcccccccccc}
\hline Constructs & CR & AVE & MSV & 1 & 2 & 3 & 4 & 5 \\
\hline Fund availability & 0.866 & 0.668 & 0.002 & $\mathbf{0 . 9 3 1}$ & & & & & \\
Outsourcing & 0.890 & 0.606 & 0.603 & 0.044 & $\mathbf{0 . 7 7 9}$ & & & \\
Preventive maintenance & 0.910 & 0.717 & 0.175 & 0.043 & -0.053 & $\mathbf{0 . 8 4 7}$ & & \\
Corrective maintenance & 0.870 & 0.635 & 0.175 & -0.036 & 0.004 & 0.417 & $\mathbf{0 . 7 9 7}$ & \\
Rentals & 0.959 & 0.731 & 0.091 & 0.047 & 0.011 & 0.586 & 0.075 & $\mathbf{0 . 8 5 4}$ \\
Halting production & 0.871 & 0.642 & 0.083 & 0.017 & 0.081 & 0.494 & 0.024 & 0.061 & $\mathbf{0 . 8 0 1}$ \\
Satisfaction business goals & 0.895 & 0.729 & 0.445 & 0.095 & -0.067 & 0.304 & 0.061 & 0.086 & 0.052 & $\mathbf{0 . 8 5 4}$ \\
\hline
\end{tabular}


Firm productivity, profit and business goal satisfaction: an assessment of maintenance decision effects on Small and Medium Scale Enterprises (SME's)

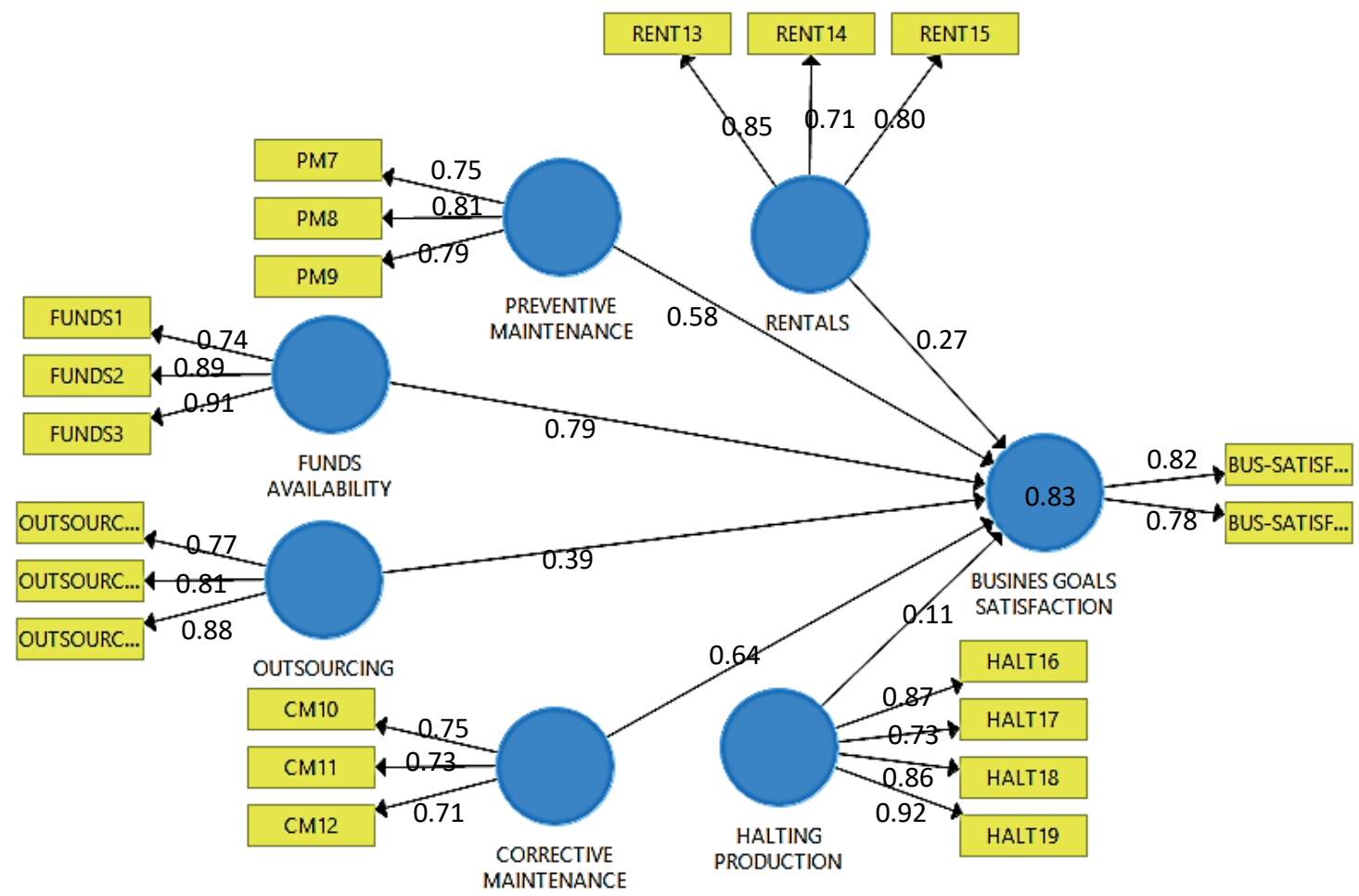

Figure 2: Relationship between maintenance decision factors and business goal satisfaction as perceived by firm managers using the Structural Equation Modeling-Partial Least Square design.

\subsection{Key parameters managers confirmed influence their maintenance decision}

Results obtained identified that the availability of funds, outsourcing possibility, preventive and corrective maintenance options, halting of production, and rental of equipment from third party firms were relevant options managers had to consider before carrying out maintenance works (Figure 2). Out of these options or variables, funds availability, and corrective and preventive maintenance option were the most significant (Figure 2).

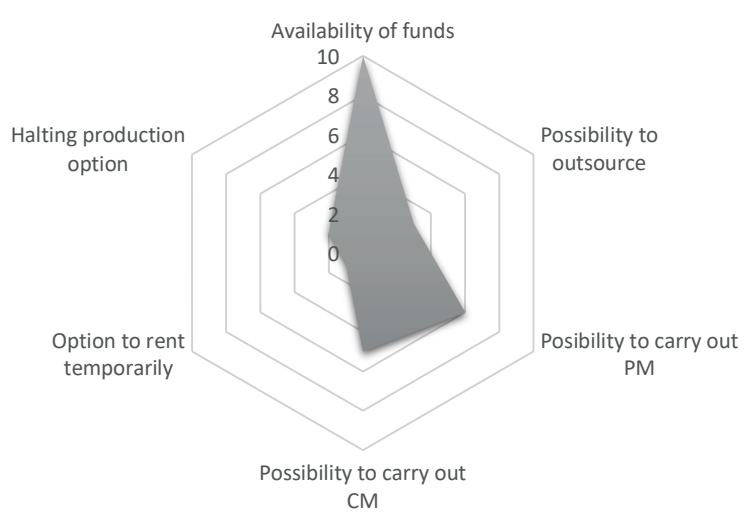

Figure 3: Relevant options that firm managers considered in their decision to carry out maintenance.

\subsection{Relationship between maintenance schedules and firm annual profit}

Management of studied firm conducted a total of 23 maintenance works over a period of six years, ranging from 1 in the first year of production to 8 in the fifth year, costing a total of USD $38,156.70$. The cost of maintenance was shown as the major determinant of profit for the firm as it significantly affected profit margins (Figure 3 ). A general trend was that whenever maintenance cost increased with increasing number of maintenance, profit margins reduced (Figure 3 ). This correlate $(0.79)$ well with the magnitude of effect availability of funds has on general management satisfaction with the realization of business goals as depicted in the model (Figure 4).

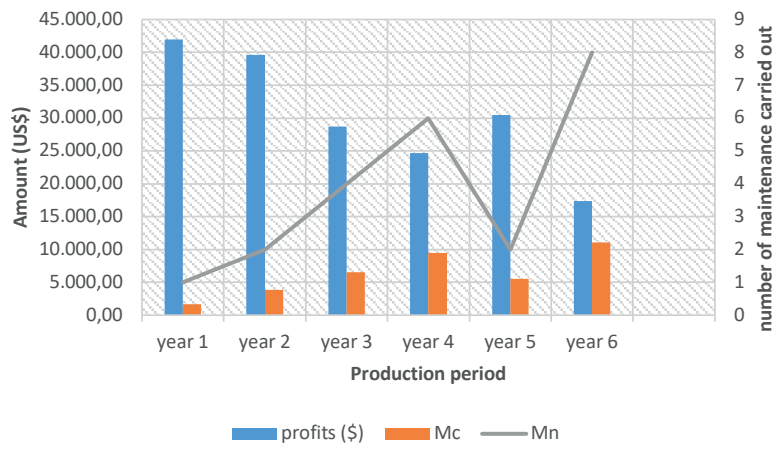

Figure 4: Relationship between number of maintenance carried out (Mn), maintenance cost (Mc) and profit over a six-year production period.

\section{Conclusion}

This study investigated the factors that most often are considered by managers of SMEs and firms in making decisions about the maintenance of production systems. Managers ranked funds availability, options for preventive 
and corrective maintenance, outsourcing option, and rentals as relevant factors they usually consider before deciding on whether or not to carry out maintenance. Among these factors, funds availability, linked with options for preventive and corrective maintenance actions, was the most relevant in determining the satisfaction of organizational goals. It was also noted in this study that, for SMEs, profit margin is highly affected by maintenance costs. Observation showed that as the number of maintenance works increased, firm profit margins reduced significantly. This was because, the budget of SMEs is highly constrained compared to larger firms with higher capital investments and technologies. Also, it was observed that SMEs had limited options that could reduce their spending whenever confronted with technical maintenance related production challenges.

\section{Acknowledgements}

The research received no external funding.

\section{References}

Al-Tabbaa, O., Ankrah, S. (2016). Social capital to facilitate 'engineered'university-industry collaboration for technology transfer: A dynamic perspective. Technological Forecasting and Social Change, 104, 1-15. https://doi.org/10.1016/j.techfore.2015.11.027

Alarcón, D., Sánchez, J.A., Pablo de Olavide, U. (2015). Assessing convergent and discriminant validity in the ADHD-R IV rating scale: User-written commands for Average Variance Extracted (AVE), Composite Reliability (CR), and HeterotraitMonotrait ratio of correlations (HTMT). In Spanish STATA Meeting (pp. 1-39). Universidad Pablo de Olavide.

Barone, G., Frangopol, D.M. (2014). Life-cycle maintenance of deteriorating structures by multi-objective optimization involving reliability, risk, availability, hazard and cost. Structural Safety, 48, 40-50. https://doi.org/10.1016/j. strusafe.2014.02.002

Bertolini, M., Bevilacqua, M. (2006). A combined goal programming-AHP approach to maintenance selection problem. Reliability Engineering \& System Safety, 91(7), 839-848. https://doi.org/10.1016/j.ress.2005.08.006

Hair, Jr, Joseph, F., Tomas, G., Hult, M., Ringle, C., Sarstedt, M. (2016). A primer on partial least squares structural equation modeling (PLS-SEM). Sage publications.

Jiang, R., Murthy, D.N.P. (2008). Maintenance: Decision Models for Management. Science press, Beijing, China.

Joo, S-J. (2009). Scheduling preventive maintenance for modular designed components: A dynamic approach. European Journal of Operational Research, 192(2), 512-520. https://doi.org/10.1016/j.ejor.2007.09.033

Lee, H. (2005). A cost/benefit model for investments in inventory and preventive maintenance in an imperfect production system. Computers and Industrial Engineering, 48(1), 55-68. https://doi.org/10.1016/j.cie.2004.07.008

Liu, X., Wang, W., Peng, R. (2015). An integrated production: inventory and preventive maintenance model for a multiproduct production system. Reliab Eng Syst Safety, 137(2), 76-86. https://doi.org/10.1016/j.ress.2015.01.002

Liu, X., Zheng, J., Fu, J., Ji, J., Chen, G. (2017). Multi-level optimization of maintenance plan for natural gas pipeline systems subject to external corrosion. Journal of Natural Gas Science and Engineering, 50, 64-73. https://doi.org/10.1016/j.jngse.2017.11.021

Ma, J., Cheng, L., Li, D. (2018). Road Maintenance Optimization Model Based on Dynamic Programming in Urban Traffic Network. Journal of Advanced Transportation. Article ID 4539324, 11 pages. https://doi.org/10.1155/2018/4539324

Marquez, A.C., Gupta, J.N.D. (2006). Contemporary maintenance management: process, framework and supporting pillars. Omega, 34(3), 313-326. https://doi.org/10.1016/j.omega.2004.11.003

Nourelfath, M., Nahas, N. \& Ben-Daya, M. (2015). Integrated preventive maintenance and production decisions for imperfect processes. Reliab Eng Syst Safety, 148, 21-31. https://doi.org/10.1016/j.ress.2015.11.015

Olivotti D., Passlick J., Dreyer S., Lebek B., Breitner M.H. (2018) Maintenance Planning Using Condition Monitoring Data. In: Kliewer N., Ehmke J., Borndörfer R.(eds) Operations Research Proceedings 2017. https://doi.org/10.1007/978-3-319-89920-6_72

Pallant, J. (2007). SPSS survival manual, 3rd. Edition. McGrath Hill.

Parida, A., Kumar, U. (2016). Applications and Case Studies. Maintenance performance measurement (MPM): issues and challenges. Journal of Quality in Maintenance Engineering, 12(3), 239-251. https://doi.org/10.1108/13552510610685084

Qiu, Q., Cui, L., Shen, J., Yang, L. (2017). Optimal maintenance policy considering maintenance errors for systems operating under performance-based contracts. Comput Industr Eng., 112, 147-155. https://doi.org/10.1016/j.cie.2017.08.025 
Firm productivity, profit and business goal satisfaction: an assessment of maintenance decision effects on Small and Medium Scale Enterprises (SME's)

Ruschel, E., Santos, E.A.P. \& Loures, E.D.F.R. (2017). Industrial maintenance decision-making: a systematic literature review. J Manuf Syst., 45, 180-194. https://doi.org/10.1016/j.jmsy.2017.09.003

Shayesteh, E., Yu, J., Hilber, P. (2018). Maintenance optimization of power systems with renewable energy sources integrated. Energy, 149, 577-586. https://doi.org/10.1016/j.energy.2018.02.066

Shen, J., Zhu, K. (2017). An uncertain single machine scheduling problem with periodic maintenance. Knowledge-Based Systems, 144, 32-41. https://doi.org/10.1016/j.knosys.2017.12.021

Stebbins, R. A. (2001). Exploratory research in the social sciences (Vol. 48). Sage.

Van, P.D., Bérenguer, C. (2012). Condition-based maintenance with imperfect preventive repairs for a deteriorating production system. Qual Reliab Eng., 28(6), 624-633. https://doi.org/10.1002/qre.1431

Verbert, K., Schutter, B.D., Babuska, R. (2017). Timely condition-based maintenance planning for multi-component systems. Reliab Eng Syst Safety, 159, 310-321. https://doi.org/10.1016/j.ress.2016.10.032

Yang, L., Ma, X., Zhao, Y. (2017). A condition-based maintenance model for a three-state system subject to degradation and environmental shocks. Comput Industr Eng., 105, 210-222. https://doi.org/10.1016/j.cie.2017.01.012 